\title{
Occupational Stress and Quality of Life in Nursing ${ }^{1}$
}

\author{
Aline Moraes da Silva ${ }^{2}$ \\ Universidade Católica Dom Bosco, \\ Campo Grande-MS, Brazil
}

\author{
Liliana Andolpho Magalhães Guimarães \\ Universidade Católica Dom Bosco, \\ Campo Grande-MS, Brazil
}

\begin{abstract}
To reduce the work related to stress and the psychosocial risk is not only an imperative question, but also moral. This epistemological study aims to verify the presence of the occupational stress and quality of life related to health in nursing professionals. We used three questionnaires: (a) Socio Demographic Questionnaire, (b) Job Strain Scale, and (c) Item Short Form Health Survey. Statistical analysis was performed between the questionnaires, analysis of variance (ANOVA) and simple and multiple linear regression. It was found that $60.8 \%$ of the participants see the high demand of work, $71.8 \%$ high control on the developed activity and $85.5 \%$ low social support. Related to eight dominant of quality of life, the most damaged are: pain $(\mu=$ $61.87)$ and vitality $(\mu=62.25)$. It was concluded that although in most sample experiences an intermediary risk situation to stress, the quality of life showed a damaged.
\end{abstract}

Keywords: occupational stress, quality of life, nursing

\section{Estresse Ocupacional e Qualidade de Vida em Profissionais de Enfermagem}

Resumo: Reduzir o estresse relacionado ao trabalho e os riscos psicossociais não é apenas uma questão imperativa, mas também moral. O objetivo deste estudo epidemiológico foi verificar a presença de estresse ocupacional e avaliar a qualidade de vida relacionada à saúde entre profissionais de enfermagem. Foram utilizados três questionários: (a) Questionário sociodemográfico, (b) Job Strain Scale e (c) Item Short Form Health Survey. Realizou-se análise estatística por associações entre os questionários, análise de variância (ANOVA) e regressão linear simples e múltipla. Verificou-se que $60,8 \%$ dos participantes vivenciam uma alta demanda no trabalho, 71,8\% um alto controle sobre a atividade desempenhada e 85,5\% baixo apoio social. Dos oito domínios da qualidade de vida relacionada à saúde, os mais afetados foram: dor $(\mu=61,87)$ e vitalidade $(\mu=62,25)$. Concluiu-se que, embora a maioria da amostra vivencie um risco intermediário de estresse, a qualidade de vida relacionada à saúde mostrou-se comprometida.

Palavras-chave: stress ocupacional, qualidade de vida, enfermagem

\section{Estres Ocupacional y Calidad de Vida en Profesionales de Enfermería}

\begin{abstract}
Resumen: Reducir el estres ocupacional y riesgos psicosociales no es sólo una cuestión imperativa, sino también moral. El objetivo deste estudio epidemiológico es verificar la presencia de estrés laboral y la calidad de vida relacionada con la salud en profesionales de enfermería. Se utilizaron tres cuestionarios: (a) Cuestionario sociodemografico, (b) Job Strain Scale y (c) Item Short Form Health Survey. Análisis estadístico se realizó mediante asociaciones entre los cuestionarios, análisis de varianza (ANOVA) y de regresión lineal simple y múltiple. Se encontró que $60,8 \%$ de los participantes experimentan una alta demanda en el trabajo, $71,8 \%$ un alto control sobre la actividad realizada, y $85,5 \%$ bajo apoyo social. De los ocho dominios de la calidad de vida relacionada con la salud, los más afectados fueron: dolor $(\mu=61,87)$ y la vitalidad $(\mu=62,25)$. Se concluyó que, además que la presente muestra tenga riesgo intermedio de estrés, la calidad ser comprometida.
\end{abstract}

Palabras clave: estres ocupacional, calidad de vida, enfermería

Occupational stress, according to Kakunje (2011), has long been a concern of the healthcare industry. Stressors vary between different occupations of healthcare, and indeed within an occupation, depending on the task carried out.

Nursing, according to Cacciari, Haddad, Vannuchi, and Dalmas (2013), is one of the occupations most exposed

\footnotetext{
${ }^{1}$ Article derived from the master's thesis of the first author under the supervision of the second author, presented in 2014 in the Graduate Program in Health Psychology at Universidade Católica Dom Bosco.

${ }^{2}$ Correspondence address:

Aline Moraes da Silva. Rua Rita Vieira de Andrade, $n^{\circ} 700$, casa 11, Rita Vieira. CEP 79052420. Campo Grande-MS, Brazil. E-mail: 1ili_moore@hotmail.com
}

to a high risk of tension and becoming ill. According to the National Institute for Occupational Safety and Health (NIOSH, 2008), studies have found that the following are occupational risk factors for nursing: work overload, time pressure, lack of social support at work (especially from supervisors, nurses and higher management), exposure to infectious diseases, accidents with needles or perforating or cutting material, exposure to work-related violence or threats, ambiguity and conflict of roles, sleep deprivation, lack of staff, issues related to career development, and dealing with difficult or severely ill patients.

For evaluation of the psychosocial risk of development of stress, this study is based on the theoretical-methodological 
stress model known as Demands/Control (D/C) model, proposed by Karasek (1979, as cited by Karasek et al., 1998). Karasek et al. (1998) say that Demands are psychological requirements that are necessary for accomplishing the tasks, meeting the deadlines imposed, dealing with personal conflicts, the fear of loss of employment or of not being up to date, and the lack of mental stimulus necessary for carrying out the task; while Controls refers to the margin afforded to the worker for taking of decisions about his or her task and the development of his or her individual abilities. In accordance with this theoretical model, development of stress is due to situations of high psychological demand and low latitude for decision. Johnson and Hall (1988) added a third dimension to the $\mathrm{D} / \mathrm{C}$ Model, which until then had not been considered: social support in the work. They found that this variable relieves the stressors and pressures in the work location and reduces the impacts of cardiovascular diseases.

Another subject area studied in this survey is HealthRelated Quality of Life (HRQOL). Ware (1987), one of the creators of the generic 36 Item Short Form Health Survey (SF-36) questionnaire, used in this study, defines HRQOL as the general perception of health of an individual arising from her/his state of health or treatment.

The human and organizational losses are added to the social ones. According to Steck (2012), in Brazil in 2012 the costs to society of work illnesses and accidents totaled $4 \%$ of GDP, that is to say, R\$ 165 million, which shows the need for measures to confront this problem.

This study jointly evaluates work stress by the D/C Model and the HRQOL Model. In Brazil and worldwide there are various studies that investigate stress in nursing, but few using the D/C Model which evaluates specific stressors of the work environment, or on the HRQOL of people working with nursing. Thus, a contribution is made to the diagnosis of the situations that can adversely affect the productivity, and physical and mental wellbeing, of this population.

This survey is important since nursing professionals are the largest contingent of workers in hospital units. Also, they provide nursing assistance uninterruptedly over 24 hours. The presence of stress and the absence of quality of life related to health can adversely affect the care made available to the population, and lead to serious, and often irreparable, errors.

The aim of this survey was to evaluate occupational stress and HRQOL, in a sample of nursing professionals in the University Hospital of Campo Grande, Mato Grosso do Sul, Brazil.

\section{Method}

This study was carried out on a sample of nursing professionals of a university hospital in the city of Campo Grande, in the state of Mato Grosso do Sul, Brazil. The epidemiological, cross-sectional model was employees, according to the guidelines of the psycho-sociological approach in workers' psychic health (Borges, Guimarães, \& Silva, 2013).

\section{Participants}

Of a population of 273 nursing professionals a sample was taken, by convenience, of $227(n=227)$. Of these, 126 were nursing assistants, 75 nursing technicians and 26 were nurses, who agreed to participate voluntarily. The criteria for inclusion were: working in the profession of nurse, nursing technician or nursing assistant, in units that provide 24-hour nursing care; having a statutory link with the institution, accepting participation in the survey, and signing the Informed Consent (TCLE) Form. The criteria for exclusion were: not actively working; exercising the professional activity in a general or pediatric outpatient unit, in a day hospital, in pulse therapy or a Material and Sterilization Center ('CME'), and not meeting the other criteria for inclusion.

\section{Instruments}

Job Content Questionnaire - JCQ. This was chosen to give a theoretical and methodological basis for the evaluation of work stress in this survey, to measure the psycho-social characteristics of the work for ascertainment of Control (the worker's authority to take decisions about her/his task, and control over the development of individual abilities); of the psychological Demands (psychological requirements necessary for carrying out the tasks, deadlines imposed, personal conflicts, fear of loss of job, among others) and Social Support (investigate tranquility of the working environment, cooperativeness and relationship between colleagues of the professional and supervisors).

The JCQ has no scale for evaluating stress outside the work environment (Karasek et al., 1998). In this study the reduced version of the Job Content Questionnaire (JCQ) was used - the Job Stress Scale (JSS), which comprises 17 questions, created in Sweden by Theörell et al. (1988) and adapted to Portuguese by Alves, Chor, Faerstein, Lopes and Werneck (2004). The version in Portuguese has a Cronbach's alpha of .72 for Demand, .63 for Control, and .86 for Social Support. As for the internal consistency of the instrument, the three factors have results above .81 . The scale comprises five questions on Demand and six on Control, with responses on a Likert scale of four points, varying between frequently and never or almost never; and six questions on Social Support, with responses on a Likert scale of four points, ranging from I totally agree to I totally disagree.

For the establishment of the quadrants proposed by Karasek et al. (1998), it is necessary first to attribute scores to the dimensions: psychological demand, control over the work, and social support. The scores are obtained by the sum of the points given to each one of the questions of each dimension. In the dimension of psychological Demand, each response receives a mark from 1 to 4 , a range of frequency (from never, worth 1 point, to always, worth 4), and one is scaled inversely (question 4 - always being worth 1 point, and never being worth 4), and the sum of the scores of the five answers thus varies from 5 to 20. In the dimension Control over the work, each response varies from 1 to 4 points, from the lower to higher frequency, and one answer (question 9) 
has inverse direction - the sum of the scores varying from 6 to 24. The score for social Support is obtained from the sums of the answers to the six questions, marked from 1 to 4 , from lowest to highest degree of agreement, varying from 6 to 24 .

For the definition of the quadrants of exposure to work stress and the definition of the high and low values for each segment, the median of the scores found in each one of the dimensions was attributed as the cutoff point. For the evaluation of HRQOL, it was decided to use the SF36 questionnaire which, according to Habiba et al. (2010), has been one of the instruments for evaluation of HRQOL most used currently, since it measures the health status of the population in a generic form and is self-administered. This instrument has been adapted culturally for the Brazilian population by Ciconelli (1997, as cited by Ciconelli, Ferraz, Santos, Meinão, \& Quaresma, 1999) - who consider that the reproducibility of the questionnaire in the eight domains is satisfactory and significant.

This questionnaire, comprising eight domains divided into two components, the physical and the mental, comprises 11 questions which evaluate: functional capacity, physical aspects, pain, general state of health, vitality, social aspects, emotional aspects and mental health. The evaluation of the results takes place through scores obtained for each one of the eight domains, in which zero corresponds to the worst state of health, and 100 to the best state of health.

Socio-demographic Occupational Questionnaire (Questionário Sociodemográfico-Ocupacional - QSDO). This instrument, created exclusively to serve the objects of this survey, comprises 17 questions, of which 6 are on the personal characteristics of the participants, 2 about their habits of life and 8 about variables related to the work carried out by the nurses.

\section{Procedure}

Data collection. Initially, authorization was sought to carry out the study in the University Hospital of Campo Grande, Mato Grosso do Sul. Then, visits were made to all the sectors that work uninterruptedly in providing nurse assistance, and all the workers or all the periods were invited to take part in the survey. Envelopes were delivered with the instruments and the Informed Consent Form to the nursing workers who agreed to take part in the survey, and these were collected at the end of the working day.

Data analysis. After termination of collection of data, the data were organized on spreadsheets. Statistical analysis was carried out using the Statistical Package for the Social Sciences (SPSS) software, 17th version. Simple descriptive analyses were carried out in an initial stage, and at the second stage, the variants (ANOVA) and Simple Linear Regression were analyzed, to find possible statistically significant associations between the variables of the HRQOL, the D/C Model and the SF-36. Then, all the significant associations $(p \leq .05)$ were used to assemble a Multiple Linear Regression, with a view to determining which factors contribute to the occurrence of stress and the reduction of perception of HRQOL. Considering that various variables were worked on, and that this can interfere with or at least adversely affect the explanation of the variance, after obtaining the result of the $R^{2}$ of each item of occupational stress and quality of life investigated, the option was taken to work with the adjusted $R^{2}$, to reduce the value found if the additional variable had a low power of explanation.

\section{Ethical Considerations}

This project was submitted to evaluation by the Research Ethics Committee of Universidade Católica Dom Bosco (UCDB) and approved under Opinion No. 385.857 and CAAE: 21071213.0.0000.5162.

\section{Results}

\section{Characterization of the Sample}

The age group with the highest concentration of participants $(68.5 \%)$ is the over 41 group. Of these, the majority $(72.1 \%)$ are female, and $43.1 \%$ have two children. As to schooling, participants were found to be seeking higher qualification: the staff included people studying in higher education, specialization, master's degrees and doctorates, as well as specialists, and people with master's degrees and doctorates. Only $10.1 \%$ of the participants have another employment.

\section{Characterization of the Sample as to Work Stress and Social Support}

It was found that $60.8 \%$ of the participants perceive a high psychological demand, and that the majority (71.8\%) believe that they have a high degree of control over their work, while $85 \%$ consider the social support received to be low, with difficulties in interpersonal work relationships. The majority of the participants experience active work (44.5\%), characterized by high demand and control.

In relation to demand, the nurses perceive it as being higher than that for the nursing technicians and nursing assistants $(p=.007)$. Longer time of service in the institution to date is significantly associated with the perception of degree of control over the activity carried out $(p=.001)$. Social support was perceived as lower by the nursing assistants $(p=$ $.001)$, by workers over the age of $60(p=.015)$, by females $(p=.031)$, by those who carry out extra duty hours both in the evening and at night $(p=.046)$ and by those who exercise the function of nursing technician in their second formal employment $(p=.047)$.

After verification of the existence of statistically significant associations between HRQOL, demand, control and social support from the descriptive analysis of the data and from the ANOVA, a Multiple Linear Regression was carried out to identify how much each factor with significant association interferes in the components of the JSS (Job Stress Scale) (Table 1). 
The function exercised accounted for $4.3 \%$ of participants' perception in relation to demand. Number of years working in the institution accounted for $6.4 \%$ of the perception of control over the activity carried out. Gender accounted for $12.6 \%$ of the social support; females perceived the support as lower. The function carried out corresponded to $9 \%$ of the social support; the nursing technicians and nursing assistants presented worse results. The function exercised in the other job reduces the perception of social support by $8.7 \%$, and the lower scores for social support are perceived by the workers who carry out the function of nursing technicians in their second formal employment. Age influences social support for $1.5 \%$ of the workers over 60 years of age, who perceive lower social support in the working environment. The period of duty reduces the workers' social support by $0.3 \%$, and those who carry out duty periods during the day and during the night are the most affected.

Table 1

Multiple Linear Regression of the Factors With Significant Association for the Components of the JSS

\begin{tabular}{llll}
\hline Components & $\left(\eta^{2}\right)$ & $R^{2}$ & $R^{2}$ adjusted \\
\hline Demand & & & \\
Function & .043 & .043 & .035 \\
Control & & & \\
Time with Institution & .064 & .064 & .061 \\
Social support & & & \\
Gender & .126 & .492 & .425 \\
Function & .090 & & \\
Duty period & .003 & & \\
Function in other job & .087 & \\
Age & .015 & \\
\hline
\end{tabular}

\section{Characterization of the Sample as to HRQOL}

The results found for each one of the eight dimensions are presented in Table 2 .

Table 2

Result of the Eight Domains of the SF-36

\begin{tabular}{lccc}
\hline SF-36 domains & Min & Max & $M(S D)$ \\
\hline FC & 15 & 100 & $77.62(19.51)$ \\
LPA & 00 & 100 & $77.53(36.62)$ \\
Pain & 00 & 100 & $61.87(22.10)$ \\
GSH & 15 & 100 & $72.37(18.65)$ \\
VITALITY & 05 & 100 & $62.25(19.92)$ \\
SA & 00 & 100 & $71.26(25.24)$ \\
LEF & 00 & 100 & $76.36(35.53)$ \\
MH & 28 & 100 & $84.02(16.51)$ \\
\hline NOF.
\end{tabular}

Note. $\mathrm{FC}=$ functional capacity, $\mathrm{LPA}=$ limitations due to physical aspects, $\mathrm{GSH}=$ general state of health, $\mathrm{SA}=$ social aspects, $\mathrm{LEF}=$ limitations due to emotional factors, $\mathrm{MH}=$ mental health.
The domain that presented the best score was mental health, with a value of $84.02(S D=16.51)$, and the domains that presented the lowest scores were vitality, with 62.25 $(S D=62.25)$, and pain, with $61.87(S D=22.10)$. For better comprehension of the factors that influence the results of the eight domains of the SF-36, they were associated with the data of the HRQOL.

In relation to age, the eight domains of the SF-36 showed reduction of average scores as age increased, the factor which most altered over time being functional capacity, presenting an average of $90(S D=10)$ in the 20-30 age group, and reducing to $69.09(S D=19.08)$ in workers with age above $60(p=.007)$.

Women presented lower scores than men in all the domains, except in limitations due to physical aspects. The most prejudiced domains are functional capacity $(p=.002)$, vitality $(p=.028)$ and mental health $(p=.090)$. The workers with the worst quality of life indices are the nurses, who present lower scores than those of the nursing technicians and nursing assistants in all the domains, except in functional capacity. The most compromised domains, in diminishing order, are vitality $(p=.044)$, social aspects $(p=.005)$ and limitations due to emotional aspects $(p=.004)$. Nursing professionals that have two formal employments show worse scores in all the domains of the SF-36, except for limitations due to physical aspects. The domains most prejudiced are pain, vitality and social aspects $(p=.048)$.

The workers that exercise the function of nursing technician in their second formal employment present a state of health with scores above 90 in all the domains, thus presenting an excellent state of health. However, the professionals that exercise other functions present much lower scores. In all the situations, the domains most prejudiced are pain $(p=.039)$, vitality and social aspects $(p=$ .047). Having children influences all the domains of the SF36 , and the domain most affected is functional capacity, with a statistically significant association $(p=.015)$.

After it was found that there are significant associations between the HRQOL and the SF-36, a Multiple Linear Regression was carried out (Table 3) to identify how much each factor influences in the domains of the SF-36 with statistically significant association.

As presented in Table 3, five domains of the SF-36 are most reduced in the sample as a whole: functional capacity, pain, vitality, social aspects and limitations due to emotional aspects. In relation to functional capacity, the factors associated are: (a) presence of the person's children ( $p=$ .001 ): workers with children presented $5 \%$ loss of functional capacity; (b) being female $(p=.024)$ : women presented a reduction of $2.4 \%$ in their functional capacity; and (c) age over $60(p=.008)$ : professionals aged over 60 presented a reduction of $0.8 \%$ in the functional capacity. Together, these factors accounted for a loss of $9.3 \%$ of functional capacity.

The domain with the highest score was pain $(p=.039)$, in workers carrying out the function of nurse and other functions, with the exception of nursing technician working in her/his second formal employment. The domain vitality was prejudiced by the function exercised in the institution 
Table 3

Multiple Linear Regression of the Factors With Significant Association for the Domains of the SF-36 Questionnaire

\begin{tabular}{lllc}
\hline Domains & $\left(\mathrm{n}^{2}\right)$ & $R^{2}$ & $R^{2}$ adjusted \\
\hline Functional capacity & & & \\
Children & .050 & .093 & .081 \\
Gender & .024 & & \\
Age & .008 & & \\
Pain & & & .205 \\
Function in other job & .277 & .277 & \\
Vitality & & & .040 \\
Function & .026 & .057 & \\
Gender & .024 & & \\
Other job & .009 & & \\
Social aspects & & & \\
Function & .044 & .288 & \\
Function in other job & .015 & & \\
Other job & .242 & & \\
LEF & & .028 \\
Function & .030 & & \\
\hline
\end{tabular}

$(p=.054)$, gender $(p=.021)$ and the fact of having another employment $(p=.048)$. The function carried out in the institution diminished vitality by $2.6 \%$ - nurses presenting lower vitality than nursing technicians and nursing assistants. Women presented $2.4 \%$ less vitality than men, and having another formal employment resulted in vitality $0.9 \%$ lower. Together, the function exercised, gender, and a double employment were responsible for reducing vitality by $5.7 \%$.

The domain social aspects is influenced by having another employment $(p=.048)$, by the function exercised $(p=.005)$ and by the function exercised in the second employment $(p=.047)$. As demonstrated above, nurses are the professionals that present the greatest reduction in the social aspects domain. Having another job is responsible for a decrease of $24.4 \%$ in the social aspects; the function exercised, for $4.4 \%$; and exercising another function other than nursing technician, $1.5 \%$. Together, these factors account for $28.8 \%$ of the decrease in the social aspects.

The limitations of $3 \%$ in emotional aspects $(p=.004)$ are attributed to the function exercised in the institution - the nurses present lower scores than the nursing technicians and nursing assistants.

\section{Discussion}

It was found that the age group with the highest concentration in the sample was the over- 41 group. This differs from the majority of studies found in the literature researched, in which the majority of the nursing professionals comprises young adults, aged up to 40 (Magnago, Lisboa, Griep, Zeitoune, \& Tavares, 2010; Mauro, Paz, Mauro, Pinheiro, \& Silva, 2010; Schmidt, Dantas, Marziale, \& Laus,
2009). The predominantly female sample is in accordance with the study carried out in the University Hospital of Cuiabá by Oliveira, Marcon, Conciani, and Oliveira (2014), which reported that $86.5 \%$ of nursing professionals in the institution investigated were female. The majority of participants being married or in a stable union is in harmony with the data presented in the studies of Magnago et al. (2010) and Mauro et al. (2010), according to which the majority of the nursing professionals have a personal partner.

In relation to the number of children, the findings are in accordance with the data of the survey by Tavares et al. (2014), which indicated that $50 \%$ of the professionals have at most two children. The data also corroborate the findings on the general population published in the last Brazilian census (Instituto Brasileiro de Geografia e Estatística [IBGE], 2012), which indicated that in 2010 the national fertility rate was 1.90, and in the Center-West Region of Brazil, 1.92 children per woman.

Participants having another employment were in a minority, which is probably due to the fact that the large number of extra duty periods available provides a sufficient family income, there being no need to seek other employments. In Brazil, the reality of double employment for the nursing population is real, and frequent. A study carried out by Griep, Rotenberg, Landsberg and Silva (2011) in Rio de Janeiro found that $36 \%$ of the nursing professionals carried out a double working day.

In the authors' opinion, the perception of high psychological demand is inherent to nursing, because it deals 24 hours a day with human beings who are ill and who need care for maintenance of life and satisfaction of their basic human needs: hence there is an absence of slow, monotonous work that is not committed to results. A study held by the Health Department of the city of Campo Grande, in the state of Mato Grosso do Sul, by Theme Filha, Costa, and Guilam (2013), found that $42.5 \%$ of nursing professionals perceived the psychological demand as high. Probably much of the data on demand derives from the context and from the organization of work of the various institutions, as well as the type of work carried out.

The perception of high control may be the result of the work unit studied being a school hospital that offers internships for all the courses of the area of health, enabling the workers in nursing and other professionals to accompany and also give opinions on cases and illnesses, acquire new scientific and technological knowledge, and be a source of academic and professional reference for the students, also carrying out work of teaching and supervision, although not official. A study by Schmidt et al. (2009) with nursing professionals of 11 Brazilian institutions detected a high control only in the employees of the public and philanthropic institutions, corroborating the data found in this survey.

In relation to the low percentage of social support, this result may be attributed to nursing being stratified, that is to say, comprising four professional categories (nurse, nursing technician, nursing assistant and attendants), generating conflicts and divisions. A factor that can also generate low social support is the quantitative and qualitative overload of 
work due to the working day, in which the worker often, to deal with all the work, works alone, with reduced social interaction, and often one professional does not have knowledge of the problems and difficulties faced by the other. Andrade, Hoch, Vieira and Rodrigues (2012), in a study with nursing workers in public and private institutions, found lower social support in work in the case of public employees. Studies on nursing suggests and give value to social support in the work, which would improve professional performance, reducing the perception of stress and increasing the positive perception of health (Ferreira, Griep, Fonseca, \& Rotenberg, 2012).

The study by Araújo, Graça, and Araújo (2003) found a majority of its participants to be in active work, characterized by high demand and high control, being exposed to an intermediate risk of stress. This result can be attributed to the fact that those workers had been working in their functions for a long time in the institution, and thus had a higher control over the activity carried out. Also, that hospital works with a weekly workload of 30 hours, which softens the effect of the long working hours arising from overtime, causing, for the worker, a feeling of greater control over the work. These authors advised caution in analysis of situations of active work, since experimental laboratory analyses have shown that a high level of demand can block the sources of strength provided by high control, and generate situations of stress due to the effort made to obtain necessary results.

In relation to demand, the nurses report a higher psychological demand than the nursing technicians and the nursing assistants, probably due to the small number of professionals in the institution, which leads to accumulation of functions, overwork and excess responsibilities. The study by Schmidt et al. (2009) corroborates the finding of higher values of psychological demand for nurses. It is found that in the institutions studied, the control increases $(p=.001)$ in accordance with the amount of time the person has worked at the institution. A study of municipal public workers in nursing in Campo Grande, Mato Grosso do Sul by Theme Filha et al. (2013) also confirms a statistically significant association between the number of years worked so far and control over the activity carried out.

As to the lower perception of social support after the age of 60 , no corresponding data were found in the literature to enable comparisons. Social support is perceived as lower by women than by men. Even so, the possibility of communication between work colleagues and the establishment of relationships of affection at work seems to be more significant for women than for men. Social support is perceived as lower by workers that do overtime during the day and during the night (two periods) than by those that do overtime only in one period, probably due to tiredness, sleep, and conflict between the interests of home and work arising from the excessive working hours, which can also prejudice interpersonal relationships at work. A study on nurses in Australia by Dorrian et al. (2006) indicated that those that did overtime and did not have regular periods for pauses were more likely to present sleepiness, fatigue, stress, physical tiredness and mental exhaustion during the period of work. It is added that, for workers that carry out the function of nursing technician in their second job, the average values are lower than for nurses and other jobs. It was not possible to compare the results of this study with the literature, because corresponding data were not found.

In relation to HRQOL, there was a reduction of the scores for practically all of the eight domains of the SF-36 as participants got older. This information is a source of concern, since employees are admitted to the institution by public competition, and thus remain in the function of nursing assistant, nursing technician, or nurse for a long period, and the workers carry out a function of care that requires energy, vigor and disposition to be effective.

The fact that females present a lower result in various domains of the SF-36 could be due to the fact that women, as well as the excessive burden of work, are responsible for domestic duties, education of the children and care of the spouse, creating a double working day, or even a triple one. The Applied Economic Research Institute (Instituto de Pesquisa Econômica Aplicada [IPEA], 2010) estimates that women dedicate approximately 24 hours a week to domestic work, and men $9.7 \mathrm{hrs}$.

Nurses show a greater reduction in the scores of the SF36 than nursing technicians and nursing assistants. This may be due to their low number in the institution studied, which might cause an accumulation of management and support functions, reducing HRQOL. This differs from the result of a study in São Paulo by Pelliciotti and Kimura (2010), which reported no difference in average values on the SF-36 between nurses and nursing technicians.

Nursing professionals that have two formally registered jobs showed worse scores in all the domains of the SF-36, except limitations due to physical aspects. The study by Oliveira et al. (2014) corroborates this result - it found that nursing professionals with work overload and little time for relaxation attributed various problems in their personal lives, interpersonal relations and performance of their professional activities to these factors.

Having children adversely affects all the domains of the SF-36. However, the domain most affected is functional capacity. The study by Mauro et al. (2010) concluded that the complex function of women being mothers as well as nursing professionals is not simple, and causes tiredness, stress, work overload and, as a result, health problems.

That study found an intermediate level of risk for stress, with adverse effect on HRQOL, resulting in physical and mental wear and risk of illness. Thus, recognition of the potential factors for risk in this professional sector is important as a support to action aiming to reduce or combat possible adverse effects on professionals' physical and mental health.

The study carried out has implications for the field of occupational health psychology, using the approaches of epidemiology, diagnostics and work stress, in which stress is not regarded as an illness, but as an attempt by the worker to adapt to the process of work. Because it is a cross-sectional study, and thus shows only a momentary portrait of the reality experienced by nursing workers in a university hospital, the results of this study can be considered to be limited.

It is hoped that the results of this survey can contribute 
to the promotion of nursing professionals' health and quality of life, with repercussions in the quest for a pleasurable professional activity, with less suffering, and closer to the needs of the clientele that are served, reflecting in excellence of the services provided.

\section{References}

Alves, M. G. M., Chor, D., Faerstein, E., Lopes, C. S., \& Werneck, G. L. (2004). Short version of the "Job Stress Scale": A Portuguese-language adaptation. Revista de Saúde Pública, 38(2), 164-171. doi:10.1590/S003489102004000200003

Andrade, T., Hoch, R. E. S., Vieira, K. M., \& Rodrigues, C. M. C. (2012). Síndrome de burnout e suporte social no trabalho: A percepção dos profissionais de enfermagem de hospitais públicos e privados [Burnout Syndrome and social support at work: The perception of the nursing professionals at public and private hospitals]. Organizações \& Sociedade, 19(61), 231-251. doi:10.1590/S1984-92302012000200004

Araújo, T. M., Graça, C. C., \& Araújo, E. (2003). Estresse ocupacional e saúde: Contribuições do Modelo Demanda-Controle [Occupational stress and health: Contributions of the Demand-Control Model]. Ciência \& Saúde Coletiva, 8(4), 991-1003. doi:10.1590/S141381232003000400021

Borges, L. O., Guimarães, L. A. M., \& Silva, S. S. (2013). Diagnósticos e promoção da saúde psíquica no trabalho [Diagnostics and promotion of mental health at work]. In L. O. Borges \& L. Mourão (Eds.), O trabalho e as organizações: Atuações a partir da psicologia [Work and organizations: Performances from psychology] (pp. 581618). Porto Alegre, RS: Artmed.

Cacciari, P., Haddad, M. C. L., Vannuchi, M. T. O., \& Dalmas, J. C. (2013). Estado de saúde de trabalhadores de enfermagem em readequação e readaptação funcional [Health status of nursing workers in functional retraining and readaptation]. Revista Brasileira de Enfermagem, 66(6), 860-865. doi:10.1590/S0034-71672013000600008

Ciconelli, R. M., Ferraz, M. B., Santos, W., Meinão, I., \& Quaresma, M. R. (1999). Tradução para língua portuguesa e validação do questionário genérico de avaliação de qualidade de vida SF-36 (Brasil SF-36) [BrazilianPortuguese version of the SF-36. A reliable and valid quality of life outcome measure]. Revista Brasileira de Reumatologia, 39(3), 143-150.

Dorrian, J., Lamond, N., van den Heuvel, C., Picombe, J., Rogers, A. E., \& Dawson, D. (2006). A pilot study of the safety implications of Australian nurses' sleep and work hours. Chronobiology International, 23(6), 1149-1163. doi:10.1080/07420520601059615

Ferreira R. C., Griep, R. H., Fonseca, M. J. M., \& Rotenberg, L. (2012). A multifactorial approach to sickness absenteeism among nursing staff. Revista de Saúde Pública, 46(2), 259-268. doi:10.1590/S0034-89102012005000018

Griep, R. H., Rotenberg, L., Landsbergis, P., \& Vasconcellos-
Silva, P. R. (2011). Combined use of job stressmodels and self-rated health in nursing. Revista de Saúde Pública, 45(1), 145-152. doi:10.1590/S0034-89102011000100017

Habiba, M., Julian, S., Taub, N., Clark, N., Rachid, A., Baker, R., \& Szczepura, A. (2010). Limited role of multiattribute utility scale and SF-36 in predicting management outcome of heavy menstrual bleeding. European Journal of Obstetrics \& Gynecology and Reproductive Biology, 148(1), 81-85. doi:10.1016/j.ejogrb.2009.09.021

Instituto Brasileiro de Geografia e Estatística. (2012). Censo demográfico 2010: Nupcialidade, fecundidade e migração resultados da amostra [2010 population census: nuptialiy, fertility, and migration: results of the sample]. Rio de Janeiro, RJ: IBGE.

Instituto de Pesquisa Econômica Aplicada. (2010). Mulher e trabalho: Avanços e continuidades [Women and work: advances and continuities]. Brasília, DF: IPEA.

Johnson, J. V., \& Hall, E. M. (1988). Job strain, workplace social support, and cardiovascular disease: A cross sectional study of random sample of the Swedish working population. American Journal of Public Health, 78(10), 1336-1342.

Kakunje, A. (2011). Stress among health care professionals: The need for resiliency. Online Journal of Health and Allied Sciences, 10(1), 1-2. Retrieved from http:// cogprints.org/7952/8/2011-1-1.pdf

Karasek, R., Brisson, C., Kawakami, C., Houtman, I., Bongers, P., \& Amick, B. (1998). The Job Content Questionnaire (JCQ): An instrument for internationally comparative assessments of psychosocial job characteristics. Journal of Occupational Health Psychology, 3(4), 322-355. doi:10.1037/1076-8998.3.4.322

Magnago, T. S. B. S., Lisboa, M. T. L., Griep, R. H., Zeitoune, R. C. G., \& Tavares, J. P. (2010). Working conditions of nurses: Evaluation based on the demand-control model. Acta Paulista de Enfermagem, 23(6), 811-817. doi:10.1590/S0103-21002010000600015

Mauro, M. Y. C., Paz, A. F., Mauro, C. C. C., Pinheiro, M. A. S., \& Silva, V. G. (2010). Condições de trabalho da enfermagem nas enfermarias de um hospital universitário [Working conditions of the nursing team in the patient wards of an university hospital]. Escola Anna Nery, 14(2), 244-252. doi:10.1590/S1414-81452010000200006

National Institute for Occupational Safety and Health. (2008). Exposure to stress? Occupational hazards in hospitals. Cincinnati, OH: NIOSH.

Oliveira, A. G. B., Marcon, S. R., Conciani, M. E., \& Oliveira, J. R. T. (2014). Qualidade de vida entre trabalhadores de enfermagem de um hospital universitário [Quality of life among nursing workers of a university hospital]. Espaço para Saúde, 15(1), 6-13.

Pelliciotti, J. S. S., \& Kimura, M. (2010). Medications errors and health-related quality of life of nursing professionals in intensive care units. Revista Latino-Americana de Enfermagem, 18(6), 1062-1069. doi:10.1590/S010411692010000600004

Schmidt, D. R. C., Dantas, R. A. S., Marziale, M. H. P., \& Laus, 
A. M. (2009). Estresse ocupacional entre profissionais de enfermagem do bloco cirúrgico [Occupational stress among nursing staff in surgical settings]. Texto \& Contexto - Enfermagem, 18(2), 330-337. doi:10.1590/ S0104-07072009000200017

Steck, J. M. (2012, 24 de abril). Brasil gasta até 4\% do PIB com acidentes e doenças do trabalho [Brazil spends up to $4 \%$ of GDP on accidents and occupational diseases]. Jornal do Senado Federal. Retrieved from http://www12. senado.gov.br/jornal/edicoes/2012/04/24/brasil-gastaate-4-do-pib-ao-ano-com-acidentes-e-doencas-dotrabalho

Tavares, J. P., Magnago, T. S. B. S., Beck, C. L. C., Silva, R. M., Prestes, F. C., \& Lautert, L. (2014). Prevalence of minor psychiatric disorders in nursing professor. Escola Anna Nery, 18(3), 407-414. doi:10.5935/14148145.20140058

Theme Filha, M. M., Costa, M. A. S., \& Guilam, M. C. R. (2013). Occupational stress and self-rated health among nurses. Revista Latino-Americana de Enfermagem, 21(2), 475-483. doi:10.1590/S0104-11692013000200002

Theörell, T., Perski, A., Akersdedt, T., Sigala, F., AhlbergHultén, G., Svensson, J., \& Eneroth, P. (1988). Changes in job strain in relation to changes in physiological state. A longitudinal study. Scandinavian Journal of Work, Environment and Health, 14(3), 189-196. doi:10.5271/ sjweh.1932

Ware, J. E., Jr. (1987). Standards for validating health measures: Definition and content. Journal Chronic Diseases, 40(6), 473-480.

Aline Moraes da Silva holds a M.S. in Health Psychology from Universidade Católica Dom Bosco.

Liliana Andolpho Magalhães Guimarães is a Professor at Universidade Católica Dom Bosco.

Received: Mar. 27, 2015

1st Revision: July 8, 2015

Approved: July 28, 2015

How to cite this article:

Silva, A. M., \& Guimarães, L. A. M. (2016). Occupational stress and quality of life in nursing. Paidéia (Ribeirão Preto), 26(63), 63-70. doi:10.1590/1982-43272663201608 